\title{
Evidence for Third-Order Initiation in Monomer in Thermal Polymerization of Styrene
}

\author{
Katsukiyo ITO \\ Government Industrial Research Institute, \\ Nagoya Kita-ku, Nagoya 462, Japan
}

(Received May 10, 1986)

\begin{abstract}
KEY WORDS Thermal Polymerization / Styrene / Polymerization Rate / Third-Order Initiation / Wide Range of Conversion / Molecular Weight /
\end{abstract}

The order of initiation in monomer in thermal polymerization of styrene was reported to be a second order by Schulz. ${ }^{1}$ The second-order initiation is related to the formation of biradical. However, Mayo $^{2}$ reported a third-order initiation rate, where the formation of monoradicals through Diels-Alder adducts is important for the thermal initiation. $^{2}$ The difference between the secondorder and third-order was related to the concentration of monomer, where $R_{\mathrm{th}} \propto[\mathrm{M}]^{3}$ at $[\mathrm{M}]<2 \mathrm{moldm}^{-3}$ and $R_{\mathrm{th}} \propto[\mathrm{M}]^{2}$ at $[\mathrm{M}]>$ $2 .^{2,4-6}$ For the thermal polymerization of styrene in diethyl adipate, it was found that $R_{\text {th }} \propto[\mathrm{M}]^{2}$ at $[\mathrm{M}]>0.7^{7}$ In the other papers, ${ }^{8-11} R_{\mathrm{th}} \propto[\mathrm{M}]^{2}$ or $[\mathrm{M}]^{3}$ was used on the basis of the above. However, in the above experiments, the respective order of initiation was estimated from the data obtained using appropriate solvents. Usually, the viscosity of polymerization system varies with the fraction of solvent and the molecular weight of polymer formed depends on the concentration of monomer. ${ }^{12,13}$ These are related to termination rate, as $k_{\mathrm{t}} \propto g(\eta, n)=g([\mathrm{M}])$, as shown in ref 14 . Then the order observed in monomer should be deviated from $R_{\mathrm{pth}} \propto$ $[\mathrm{M}]^{(1+\delta / 2)}$. In spite of such deviations, the order of $R_{\mathrm{th}}$ in [M] has been calculated by $R_{\mathrm{th}}$ $g([\mathrm{M}])\left(R_{\mathrm{pth}} /[\mathrm{M}]\right)^{2}$. That is, the polymeriza- tion rate is quite sensitive to the concentration of monomer. Accordingly, it may be difficult to examine the difference between $[\mathrm{M}]^{2}$ and $[\mathrm{M}]^{3}$ using solvents. In the present paper, the order of initiation in [M] is determined in the absence of solvents. Thus, the order obtained is independent of the above difficulties.

The rate of polymerization initiated by both the primary radicals formed by decomposition of the initiator and those formed thermally is given by:

$$
R_{\mathrm{p}}=\left(2 f k_{\mathrm{d}}[\mathrm{C}]+k_{\mathrm{th}}[\mathrm{M}]^{\sigma}\right)^{1 / 2}\left(k_{\mathrm{p}} / k_{\mathrm{t}}^{1 / 2}\right)[\mathrm{M}]
$$

The $x-t$ curve observed at $100.0^{\circ} \mathrm{C}$ in the presence of 2-phenyl-azo-2,4-dimethyl-4methoxyvaleronitrile (PADMV) as an initiator $[C]_{0}=15 \mathrm{mM} \mathrm{dm}^{-3}$ ) is shown in Figure 1 . In the absence of the initiator $([C]=0)$, eq 1 is reduced to:

$$
R_{\mathrm{pth}}=\left(k_{\mathrm{p}} / k_{\mathrm{t}}^{1 / 2}\right)\left(k_{\mathrm{th}}[\mathrm{M}]^{\sigma}\right)^{1 / 2}[\mathrm{M}]
$$

The $x-t$ curve observed in the absence of the initiator is also shown in Figure 1. As stated previously, because of $k_{1} \propto g(n)=g([\mathrm{M}])$ a valid estimation of $\sigma$ may be impossible when unreactive polymers are formed by termination. ${ }^{14}$ Especially, at high conversion, the dependence of $k_{\mathrm{t}}$ on $n$ is quite marked. However, when transfer predominates, the dependence is negligibly small. ${ }^{15}$ On the pre- 


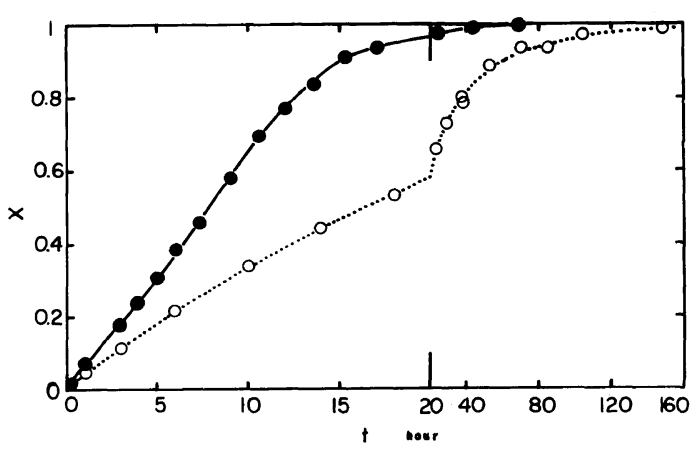

Figure 1. The $x-t$ curves obtained at $100.0^{\circ} \mathrm{C}$ where (O): $[\mathrm{C}]_{0}=15 \mathrm{mMdm}^{-3}$ and $(\mathrm{O})$ : $[\mathrm{C}]=0$. Polymerization was carried out by the previously described. ${ }^{15}$ Conversion was measured by gravimetry.

dominant transfer, we obtain:

$$
2 / p_{\mathrm{w}}=C_{\mathrm{trM}}+C_{\mathrm{trP}}[\mathrm{P}] /[\mathrm{M}]
$$

To estimate $p_{\mathrm{w}}$, we can use: ${ }^{14}$

$$
p_{\mathrm{w}}=\mathrm{d}\left(P_{\mathrm{w}} x\right) / \mathrm{d} x
$$

The relationship between $P_{\mathrm{w}} x$ and $x$ is shown in Figure 2. The $p_{\mathrm{w}}$ of polymer formed in the initial stage is found to be 6200 when $[C]=0$ and 4800 when $[C]_{0}=15 \mathrm{mMdm}^{-3}$. In the initial stage, $g(4800)$ is approximated to $g(6200)$, because the dependence of $k_{\mathrm{t}}$ on $n$ is not marked. ${ }^{14}$ Both the $p_{\mathrm{w}}$ for $0 \leqslant x \leqslant$ 0.1 when $[C]=0$ and that for $0 \leqslant x \leqslant 0.2$ when $[C]_{0}=15$ increase with increasing $x$. The value of $p_{\mathrm{w}}$ remains 6800 for $0.1 \leqslant x \leqslant 0.9$ when $[\mathrm{C}]=0$ and for $0.2 \leqslant x \leqslant 0.9$ when $[\mathrm{C}]_{0}$ $=15$, as estimated from the slopes of the lines in Figure 2. Above $x=0.9, p_{\mathrm{w}}$ increases with increasing $x$ where the value of $p_{\mathrm{w}}$ when $[C]=0$ is equal to that when $[C]_{0}=15$, and $C_{\mathrm{trM}}$ is comparable to $C_{\mathrm{tr}}[\mathrm{P}] /[\mathrm{M}]$. Thus, the value of $k_{\mathrm{t}}$ when $[\mathrm{C}]=0$ agrees very much with that when $[C]_{0}=15$ in the whole range of conversion. Such agreement was also observed in the polymerization of methyl methacrylate when the initiation rate was very low. ${ }^{15}$ The values of $f$ and $k_{\mathrm{p}}$ should also be constants in nearly the whole range of conversion. ${ }^{15,16}$ Then, eq 1 and 2 yield:

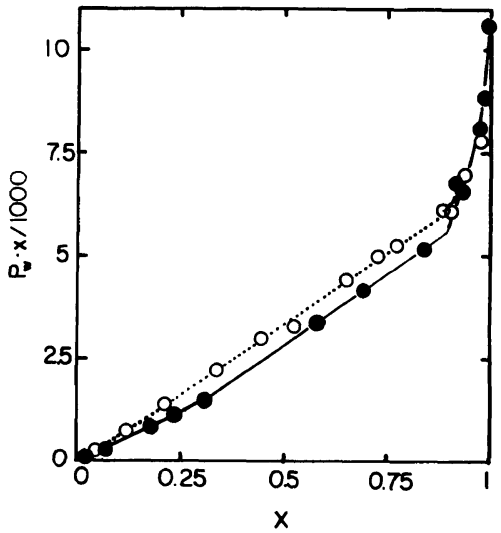

Figure 2. Relationship between molecular weight and conversion where $(O):[C]_{0}=15 \mathrm{mM} \mathrm{dm}^{-3}$ and $(O):[C]$ $=0$. The molecular weight was measured by the light scattering method. ${ }^{15}$

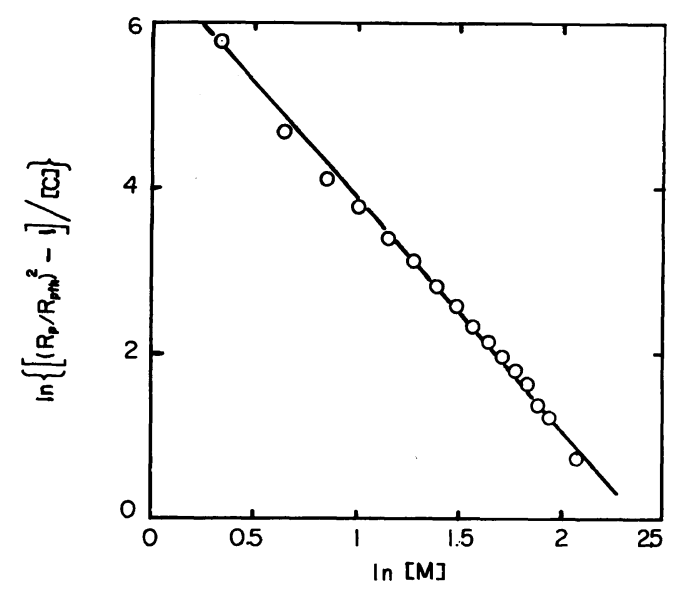

Figure 3. Relationship between $R_{\mathrm{p}} / R_{\mathrm{pth}}$ and [M].

$$
\begin{aligned}
\ln \left[\left(R_{\mathrm{p}} / R_{\mathrm{pth}}\right)^{2}-1\right] /[\mathrm{C}]= & \ln \left(2 f k_{\mathrm{d}} / k_{\mathrm{th}}\right) \\
& -\sigma \ln [\mathrm{M}]
\end{aligned}
$$

The relationship based on eq 6 is shown in Figure 3. Here, $[\mathrm{C}]$ is calculated by: $[\mathrm{C}]=$ $[C]_{0} \exp (-0.0083 t) .{ }^{17}$ The linearity of the relationship is quite good. We obtain $\sigma=$ $2.9 \pm 0.2$ from its slope and $2 f k_{\mathrm{d}} / k_{\mathrm{th}}=810$ from the intercept. The value as $\delta=2.9$ is very close to 3 . It is evident that the order of thermal initiation in monomer is thirdorder. In the past, to treat the kinetics at high conversion, both the second order ${ }^{6}$ and third 
$\operatorname{order}^{11}$ were used. Based the present results, the third-order initiation is better.

Applying eq 4 to the data in Figure 2, we obtain: $C_{\text {trM }}=2.9 \times 10^{-4}$, which is in agreement with $1.83 \times 10^{-4} .{ }^{18}$ The increase in $p_{\mathrm{w}}$ with increasing $x$ shows that the radical transfers to the polymer which repropagates. The polymer transfered becomes larger. This phenomenon will be discussed in the near future following more experimental work.

\section{NOMENCLATURE}

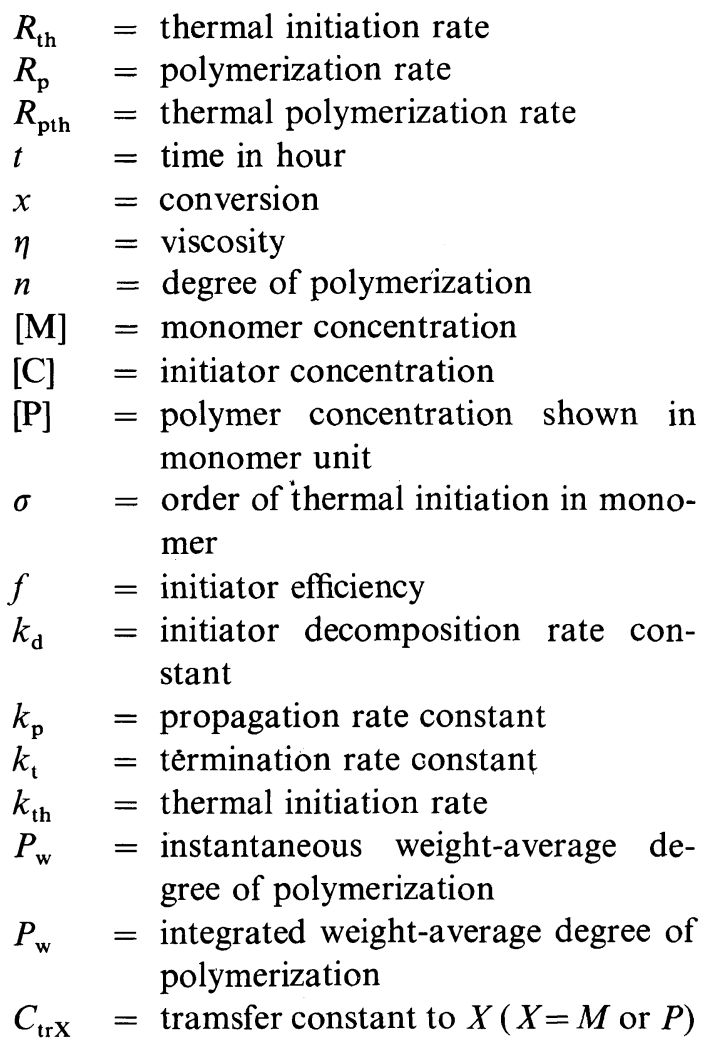

Acknowledgements. The author wishes to thank Wako Pure Chemical Industries, Ltd. for supplying the PADMV.

\section{REFERENCES AND NOTES}

1. G. V. Schultz, A. Dinger, and E. Husemann, Z. Phys. Chem., 43B, 385 (1935).

2. F. R. Mayo, J. Am. Chem. Soc., 75, 6133 (1953).

3. W. A. Pryor and L. D. Lasswell, "Advance in Free Radical Chemistry," Vol. 5, Elek, London, 1975.

4. R. R. Hiatt and P. D. Bartlett, J. Am. Chem. Soc., 75, 6133 (1953).

5. C. Walling, E. R. Briggs, and F. R. Mayo, J. Am. Chem. Soc., 63, 1145 (1946).

6. W. I. Bengough and G. B. Park, Eur. Polym. J., 15, 1579 (1977).

7. W. I. Bengough and G. B. Park, Eur. Polym. J., 14, 431 (1976).

8. K. Ito, J. Polym. Sci., Polym. Chem. Ed., 15, 1759 (1977).

9. W. A. Pryor and J. H. Coco, Macromolecules, 3, 500 (1970).

10. K. Kirchner and H. Schlapkohl, Makromol. Chem., 177, 2031 (1976).

11. D. Bhattacharya and A. E. Hamielec, Polymer, 17, 611 (1986).

12. A. M. North and G. A. Reed, Trans. Faraday Soc., 57, 859 (1961).

13. S. W. Benson and A. M. North, J. Am. Chem. Soc., 84, 935 (1962).

14. K. Ito, J. Polym. Sci., Polym. Chem. Ed., 12, 1991 (1974); ibid., 13, 401, 1297 (1975); Polym. J., 10, 795 (1979); ibid., 12, 499, 727 (1981).

15. K. Ito, Polym. J., 16, 761 (1984).

16. T. Ebihara, K. Horie, and I. Mita, Kobunshi Ronbunshu, 40, 499 (1983).

17. This value as $k_{\mathrm{d}}=0.0083 \mathrm{~h}^{-1}$ is shown by Wako Pure Chemical Industries, Ltd. The value of $[\mathrm{C}] /[\mathrm{C}]_{0}$ is calculated to be 0.85 at $x=0.95$ (20 hours) and 0.52 at $x=1$ ( 80 hours). Therefore, the decrease in [C] is not marked at $x<0.85$ in the present analysis.

18. G. Henrici-Olive and S. Olive, Forshur. Hochpolym. Forsch, 2, 496 (1961). 